\title{
INTEGRATION OF DATA OBTAINED BY PHOTOGRAMMETRIC METHODS SUCH AS A TERRESTRIAL LASER SCANNER AND UAV SYSTEM AND USE IN 3D CITY MODELS: THE CASE OF KÖYCEĞIZZ CAMPUS
}

\author{
İ. Dursun ${ }^{1 *}$, A. Varlik ${ }^{2}$ \\ ${ }^{1}$ Necmettin Erbakan University, Graduate School Natural and Applied Sciences, Geomatics Engineering, 42090, \\ Meram, Konya, Turkey (*Corresponding Author) - dursuni@tkgm.gov.tr \\ ${ }^{2}$ Necmettin Erbakan University, Engineering Faculty, Geomatics Engineering, 42090, \\ Meram, Konya, Turkey, avarlik@konya.edu.tr
}

KEY WORDS: Terrestrial Laser Scanning, Unmanned Aerial Vehicle (UAV), Level of Details (LoD), 3D City Models, LIDAR.

\begin{abstract}
:
The ever-growing and complex structure of cities has increased the need to include advanced information and communication technologies in management processes. In parallel with this, the concept of smart cities has emerged and the creation and use of three-dimensional (3D) city models have become one of the most important components for tracking cities online. Depending on technological advances; Photogrammetric methods come to the fore in surveying because it offers convenience in terms of cost and time. Among the photogrammetric methods, mobile laser scanning and UAV (Unmanned Aerial Vehicle) systems have become very popular. In this study; Necmettin Erbakan University, Faculty of Social Sciences and Humanities (SBIF), located in Köyceğiz Campus, was chosen as the study area and focused on integrating three-dimensional (3D) models produced by terrestrial and aerial photogrammetry under the theme of smart cities.
\end{abstract}

\section{INTRODUCTION}

Smart cities are living spaces where practices that increase the quality of life of people living in cities with the help of technology and minimize the negative effects of city life are implemented. In addition, they are urban structures built on an integrated information organization that has an advanced City Information System, where citizens can benefit from all services via fixed or mobile systems and provide information returns in every field. Today, "Smart City" solutions aiming to solve the problems of cities and increase the quality of life of those living in cities gain importance and are rapidly being implemented in many cities around the world. It basically implemented smart city solutions in such a way as to enable decision-making based on real-time information and integrated with the information technologies infrastructure systems of cities such as City Information System (CIS) and Geographic Information System (GIS). With the developing technology, it is seen that CIS has developed into 3D and continues with 3D City Models. The most important data generation method of 3D Urban Models is photogrammetric methods based on LIDAR and UAV technology. In recent years, the use of laser scanning systems (LIDAR systems) has been increasing rapidly in 3D modelling studies, detection of deformation areas, restoration and survey work.

\section{3D CITY MODELING}

3D city models, which are the foundation for 3D GIS; It comprises computerized 3D representations of spatial data such as land surface, buildings, roads, trees and other earth objects. The basic components of a 3D city model are digital terrain models, building models, street object models and models of green areas (Döllner et al., 2006). Different names such as "Virtual City", "Cybertown", "Cybercity" and "Digital City" are used for 3D city models (Sadek et al., 2002). In 3D city models, especially in recent years, it has been focused on obtaining a view as close to physical reality as possible and creating photorealistic views of urban objects (Döllner et al.,
2006). Many applications, such as urban planning, facility management and personal navigation programs require hosting semantic information about urban objects as well as geometry models (Mao, 2011). During the production of 3D city models, if only presentation-oriented models are produced and modeled in terms of thematic/semantic or topological information is neglected, these models can only be used for visualization, but cannot be used for thematic queries, analyzes and spatial information (Döllner et al., 2006).

The need for different content and detail level representations required for various purposes within the scope of $3 \mathrm{D}$ modeling and meeting these needs by using different data types and tools from different sources leads to the need to develop certain standards in 3D modeling over time (Doğru and Şeker, 2009). There are some standards developed to store, manage and integrate 3D city models developed in different data structures and different programs (Mao, 2011). CityGML, proposed by the Open Geospatial Consortium (OGC) in August 2008, is the first international standard to represent 3D city models (Mao, 2011). VDI 3805 and Industrial Foundation Class (IFC), developed in 2011, are among other standards (Mao, 2011). City models can be created in different ways by using developing computer technologies and programs and 3D data structures.

Today, there are many GIS software and many of this software has their own data storage formats. It is inevitable to do additional operations when sharing data from GIS software that stores in its own formats to another GIS software (Emem et al., 2008). When exchanging data between GIS software, formats such as Geographic Markup Language (GML), which can count data in one data structure to be stored directly in another data structure, are used. The data to be shared is converted into a GML document and becomes readable and usable by other software (Emem et al., 2008).

GML was developed by OGC and accepted as 19136 international standards by the International Organization for 
Standardization (ISO) in 2007. GML includes basic schema, application schemas and data documents as a concept. It is stated that the GML data structure data contains complementary information, especially the type, geometry and topology information. One of the GML application schemes is given as CityGML. CityGML is a general information model designed for 3D representation of cities. The purpose of CityGML is defined as the storage and exchange of 3D city models data (Emem et al., 2008).

The large amount of data in 3D city models for extensive regions prevents editing and displaying the data quickly. Today, this problem is solved by making modeling at a different level of detail (Level of Detail, LoD) for the purpose (Yücel and Selçuk, 2009). With modeling at different levels of detail, the communication, sharing, presentation and use of complex and large-capacity 3D city models can be provided more efficiently (Özdoğan and Başaraner, 2013).

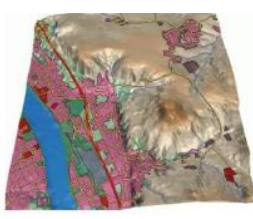

LoD0

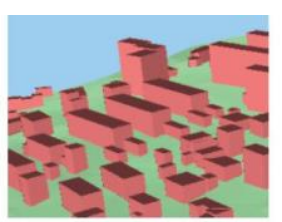

LoD1

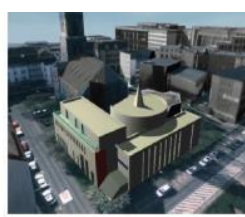

LoD2
LoD3
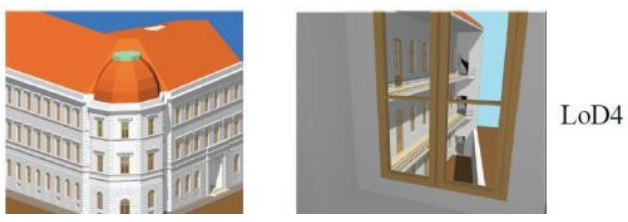

Figure 1. LoD representation defined by CityGML (Kolbe et al., 2005).

CityGML proposes 5 different levels of detail LoD for 3D city models as shown in Figure 1 (Kolbe et al., 2005). These detail levels starting from level zero and how detailed the objects in the city model will be displayed are explained below.

- $\quad$ LoD 0 is a $2.5 \mathrm{D}$ digital terrain model.

- LoD 1 is a block model with no roof structure or texture.

- LoD 2 vegetation is represented by models whose roof structure and texture can be separated.

- LoD 3 shows detailed vegetation and transportation objects with detailed wall and ceiling structures and architectural models with balconies.

- LoD 4 can also represent interior structures such as rooms, interior doors, stairs and furniture (Kolbe et al., 2005).

\section{UAV PHOTOGRAMMETRY}

It is a photogrammetry technique in which different map products such as orthophoto and point cloud are revealed as a result of the evaluation of aerial images taken by UAV with digital photogrammetric techniques, computer vision and image processing techniques (Karsl, 2020).

In this study, the DJI Phantom 4 RTK was used (Figure 2). Remote control operates this system. DJI Phantom 4 RTK is one of the most suitable solutions for 3D model production with the ability to take $1 \mathrm{~mm}$ resolution images. Integrated into the Phantom 4 RTK, the internal TRK module provides real-time, centimeter-level positioning data for improved absolute accuracy in image metadata. It enables the production of highquality orthophoto, digital elevation model, point cloud data with coordinated photo acquisition. High-resolution aerial photographs of the object are got by flying over the object for which data is to be got. Then, surface elevation models are created from these aerial photographs. On the surface height model got, laser point clouds are produced in the computer environment and the model comprising the positioned 3D point cloud $(\mathrm{X}, \mathrm{Y}, \mathrm{Z})$ of the object is got. The technical specifications of the system are given in Table 1 .

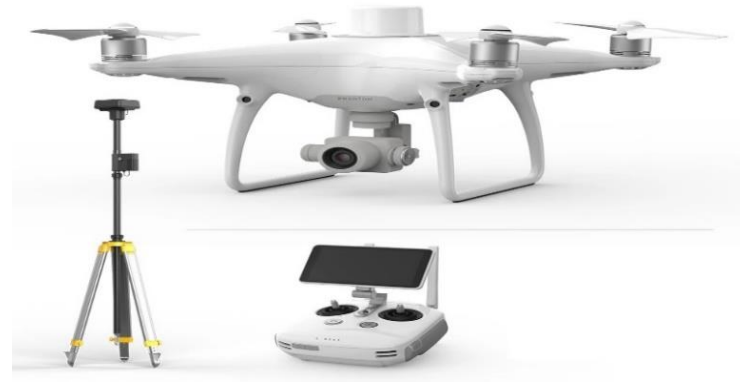

Figure 2. DJI Phantom 4 RTK UAV System.

\begin{tabular}{|c|c|c|}
\hline \multirow[t]{7}{*}{ Drone } & Takeoff Weight & 1391 gram \\
\hline & $\begin{array}{l}\text { Max Service } \\
\text { Ceiling Above } \\
\text { Sea Level }\end{array}$ & $19685 \mathrm{ft}(6000 \mathrm{~m})$ \\
\hline & Max Filght Time & Approx. 30 minutes \\
\hline & $\begin{array}{l}\text { Operating } \\
\text { Temperature } \\
\text { Range }\end{array}$ & $32^{\circ}-104^{\circ} \mathrm{F}\left(0^{\circ}-40^{\circ} \mathrm{C}\right)$ \\
\hline & $\begin{array}{l}\text { Hover Accuracy } \\
\text { Range }\end{array}$ & RTK enabled and functioning properly: Vertical : $\pm 0.1 \mathrm{~m}$; Horizontal : $\pm 0.1 \mathrm{~m}$ \\
\hline & & $\begin{array}{l}\text { RTK disabled: Vertical : } \pm 0.1 \mathrm{~m} \text { (with vision positioning) ; } \pm 0.5 \mathrm{~m} \text { (with GNSS } \\
\text { positioning) Horizontal : } \pm 0.3 \mathrm{~m} \text { (with vision positioning) ; } \pm 1.5 \mathrm{~m} \text { (with GNSS } \\
\text { positioning) }\end{array}$ \\
\hline & $\begin{array}{l}\text { Image Position } \\
\text { Offset }\end{array}$ & $\begin{array}{l}\text { The position of the camera center is relative to the phase center of the onboard D-RTK } \\
\text { antenna under the aircraft body's axis:( } 36,0 \text {, and } 192 \mathrm{~mm} \text { ) already applied to the image } \\
\text { coordinates in Exif data. The positive x, } y \text {, and } z \text { axes of the aircraft body point to the } \\
\text { forward, rightward, and downward of the aircraft, respectively. }\end{array}$ \\
\hline \multirow[t]{4}{*}{ GNSS } & \multirow{4}{*}{$\begin{array}{l}\text { Single-Frequency, } \\
\text { High-Sensitivity } \\
\text { GNSS Module }\end{array}$} & GPS+BeiDou+Galileo (Asia) \\
\hline & & GPS+GLONASS+Galileo (Other Regions) \\
\hline & & GNSS Frequency: GPS: L1/L2; GLONASS: L1/L2; BeiDou: B1/B2; Galileo: E1/E5a \\
\hline & & Speed Accuracy: $0.03 \mathrm{~m} / \mathrm{s}$ \\
\hline \multirow[t]{7}{*}{ Camera } & Sensor & 1" CMOS; Effective pixels: 20M \\
\hline & Lens & $\begin{array}{l}\text { FOV } 84^{\circ} ; 8.8 \mathrm{~mm} / 24 \mathrm{~mm}(35 \mathrm{~mm} \text { format equivalent: } 24 \mathrm{~mm}) ; \mathrm{f} / 2.8-\mathrm{f} / 11 \text {, auto focus at } \\
1 \mathrm{~m}-\infty\end{array}$ \\
\hline & ISO Range & Video:100-3200(Auto) 100-6400(Manual) ; Photo:100-3200(Auto) 100-12800(Manual) \\
\hline & \multirow[t]{2}{*}{ Shutter Speed } & Electronic Shutter Speed: 8-1/8000 s \\
\hline & & Mechanical Shutter Speed: 8 - 1/2000 s \\
\hline & \multirow[t]{2}{*}{ Max Image Size } & $3: 2: 5472 \times 3648$ \\
\hline & & 4:3: $4864 \times 3648$ \\
\hline
\end{tabular}

Table 1. DJI Phantom 4 RTK Technical Specification. 


\section{TERRESTRIAL LAZER SCANNING}

LIDAR is a technology that uses laser pulses to measure the distance of an object or a surface. LIDAR systems send millions of laser pulses per second to the object or surface to be measured. The result is a cloud of laser dots with millions of coordinates representing the scanned object. When laser scanning is compared with traditional measurement techniques, it is seen that $3 \mathrm{D}$ information is obtained at a very high speed. Laser scanning technology is very effective in identifying irregular objects (Karasaka et al., 2021). Today, many different techniques such as aerial LIDAR (ALS), mobile LIDAR (MLS), terrestrial laser scanning (TLS) or motion-to-structure (SfM) are used for dense point cloud-based mapping purposes. However, these techniques are common and effective in mapping large and large areas. Apart from the mapping of urban areas, different techniques are used in studies such as mapping indoor areas and creating inventory. One of them is the instant positioning and mapping (SLAM) algorithm-based system with LiDAR and Inertial measurement unit (IMU) integrated system (Laguela et al., 2018). New approaches are required for mapping where the relevant measurement area is small and the field of view very limited. With these approaches, lightweight wearable (WLS) or hand-held (HMLS) devices have been used for mapping purposes (Zeybek, 2019).

In this study, GeoSLAM Zeb-Revo (Geo-SLAM, 2019) handheld LiDAR scanner was tested. The resulting point clouds were reported to be produced in a relatively (RMSE $<10 \mathrm{~mm}$ ) at close range $(<10 \mathrm{~m})$ (Geo-SLAM, 2019). According to this experimentally given accuracy criterion, only distance accuracy has been tested. Horizontal and vertical positional evaluations were not made. However, in well-planned measurement networks, it has been stated that the LiDAR system has a relative error rate of 1:10000 without systematic error up to 30 minutes thanks to long loops and blocks (Dewez, Yart, Thuon, Pannet, \& Plat, 2017). In this case, it can be said that sufficient accuracy has been achieved in the arrangement of 1/1000 scale maps $(<0.08 \mathrm{~m})$.

\begin{tabular}{|l|c|}
\hline Maximum distance & $30 \mathrm{~m}$ \\
\hline Data collection speed & 43200 point/second \\
\hline Resolution & $0.625^{\circ}$ hor \\
\hline Laser safety class & $1.8^{\circ} \mathrm{ver}$ \\
\hline Laser wavelength & $905 \mathrm{~nm}$ \\
\hline $\begin{array}{l}\text { Scanner rotation } \\
\text { speed }\end{array}$ & $0.5 \mathrm{~Hz}$ \\
\hline Total system weight & $4.1 \mathrm{~kg}$ \\
\hline $\begin{array}{l}\text { Relative accuracy } \\
\text { criterion }\end{array}$ & $2-3 \mathrm{~cm}$ \\
\hline Absolute accuracy & $3-30 \mathrm{~cm}$ \\
\hline
\end{tabular}

Table 2. GeoSLAM Zeb-Revo System Technical Specification.

Zeb-Revo handheld LiDAR scanner is a time-of-flight measuring device with an IMU integrated positioning system without the need for satellite navigation systems. The scanner determines all the details around it with a simultaneous location and mapping (SLAM) algorithm (Geo-SLAM, 2019). The SLAM algorithm identifies the objects around the scanner as stationary, and according to this assumption, the points are connected and the whole point cloud is obtained (Sammartano \& Spanò, 2018). According to the GeoSLAM manufacturer, the accuracy of the measuring points is evaluated as $5 \mathrm{~mm}+1$ $\mathrm{mm} / \mathrm{m}$. Empirically, it is noted that the Zeb-Revo gives a better result than half a centimeter accuracy in well-constructed indoor studies, as its constant coefficient is noticed to be small here. The features of the product are given in Table 2.

\section{METHODOLOGY}

As an application, it will be a base for the theme of smart cities; It consists of providing the integration of the 3D Building Model created by integrating the photogrammetric data obtained by Terrestrial Laser Scanning (TLS) and Unmanned Aerial Vehicle methods. The application consists of field and office studies. For this purpose, Faculty of Social Sciences and Humanities (SBIF) located in Necmettin Erbakan University, Köyceğiz Campus has been selected (Figure 3). The model obtained at the end of the study will be a three-dimensional city model using photogrammetric data in real scale. The aforementioned three-dimensional city model is planned to be a LoD 4 level data containing interior and exterior spaces. If we list the data to be produced and the production methods below:

- LoD 2 Level: Aerial photogrammetry data obtained by Unmanned Aerial Vehicle,

- LoD 3 Level: Aerial photogrammetry data obtained by Unmanned Aerial Vehicle and data obtained by terrestrial photogrammetry method,

- LoD 4 Level: Data obtained by terrestrial photogrammetry method.

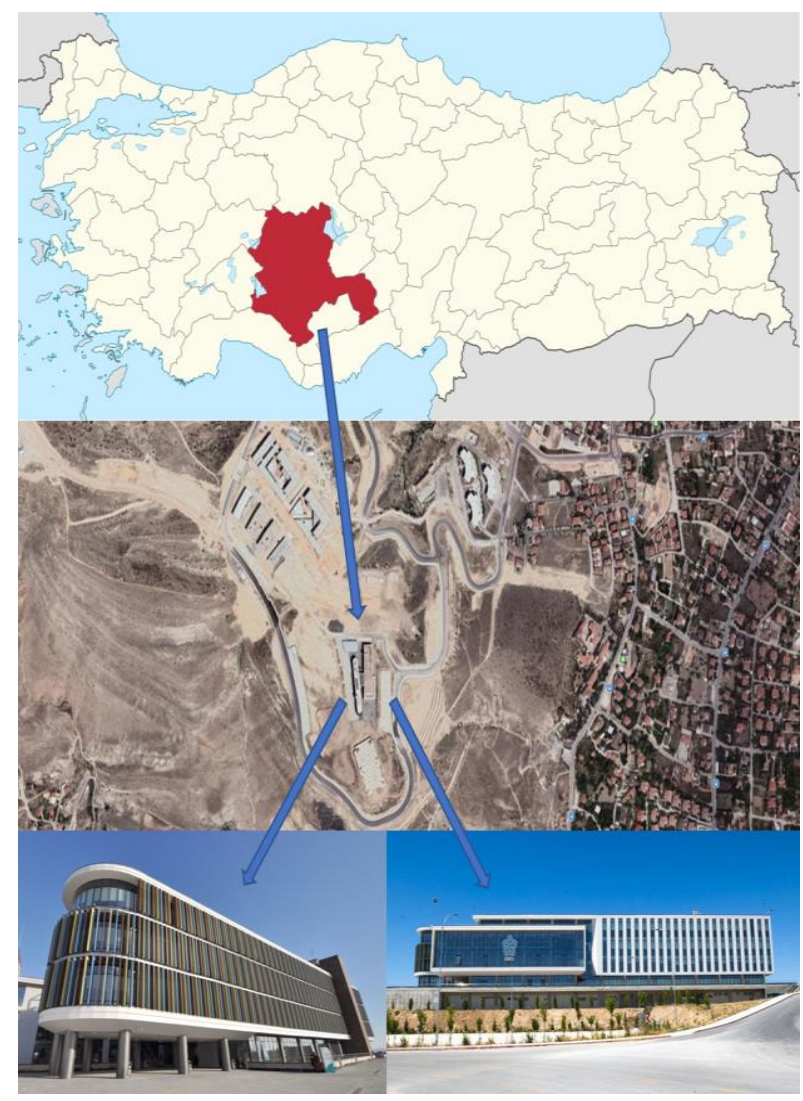

Figure 3. Working Area. 


\section{RESULTS}

We can collect Photogrammetric Data Production under two main headings. Air photogrammetry data obtained by UAV for outdoor data and LIDAR data for indoor and outdoor areas.

\subsection{Aerial Photogrammetry Data obtained by UAV}

The data obtained by the terrestrial photogrammetry method required for LoD 2 and LoD 3 Levels were produced with the DJI Phantom 4 RTK device with approximately 11 million points and used. In addition, the orthophoto of the entire campus to be used as a base was also produced with the same device (Figure 4/a and 4/b). The resulting photos were uploaded to the Pix4D software and the uploaded photos were processed. Condensed point cloud was produced from the conjugate point cloud of the combined photographs. After the ground control points are mapped, the "optimized" point cloud is coordinated and ready for output.
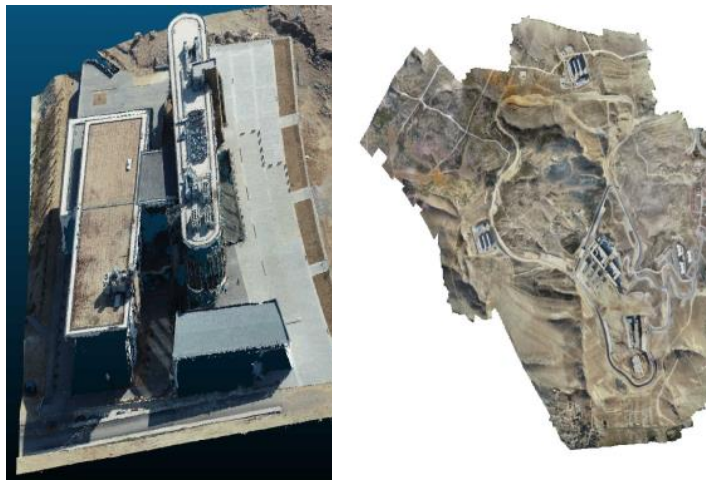

Figure 4/a. SBİF UAV Data. Figure 4/b. Campus Orthophoto.

\subsection{LIDAR}

Aerial photogrammetry data obtained with the UAV required for LoD 3 and LoD 4 Levels were performed with Zeb-Revo Hand Held Laser Scanner in 5 sessions. The data formed in these sessions are combined and consist of approximately 217 million points as shown in Figure 5/a, 5/b and 5/c. Combining and processing of 5 sessions point cloud data was done with 3DReshaper software.

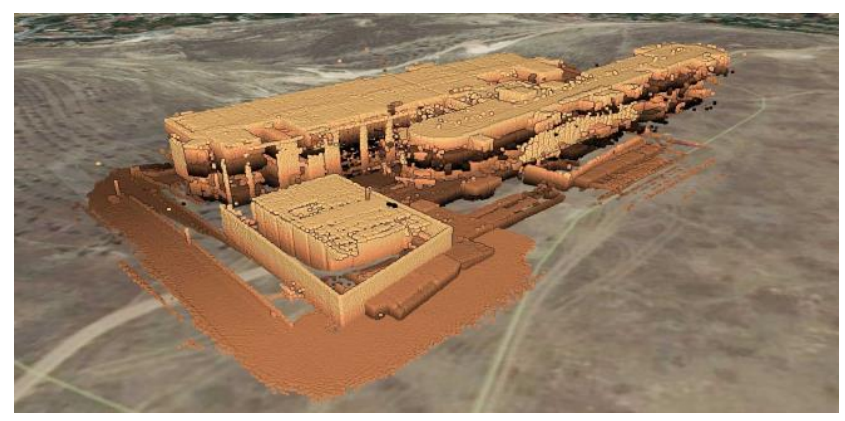

Figure 5/a. SBIF LIDAR Point Cloud.
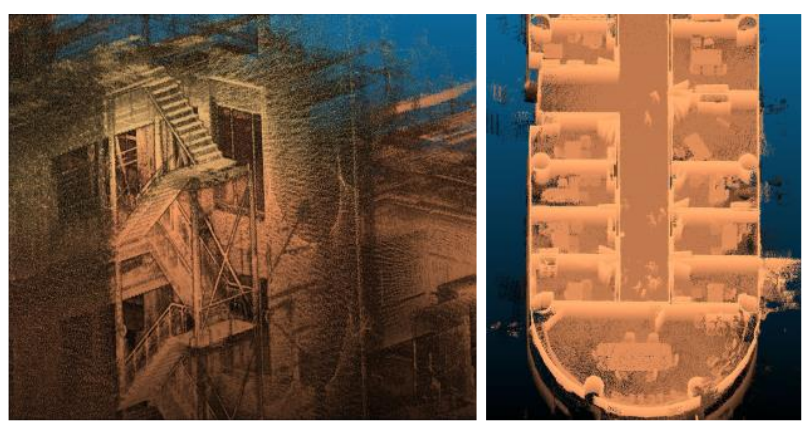

Figure 5/b. SBIF LIDAR Stairs Figure 5/c. SBIF Floor Plan.

In order to make the data more meaningful, it has been seen that it is necessary to continue with one of the options to turn into a 3D drawing (CAD) in mesh or point cloud. However, due to the fact that there are too many gaps for the model in the relevant point cloud data for the mesh operation, there are quite a few gaps in the triangulation process and sufficient quality data could not be produced. In this context, the method of transforming this data into a 3D drawing (CAD) was applied. With the help of AutoCAD software, 2D floor plans were created in CAD environment by taking sections from LIDAR data layer by layer (Figure 6/a and 6/b). In addition, the floor plan of the attic plan was obtained in the CAD environment with the aerial photogrammetry data obtained by the UAV.

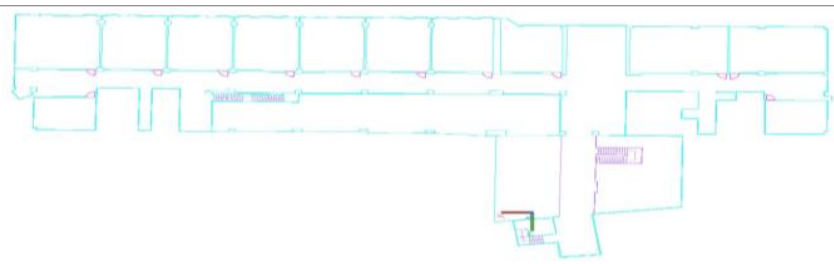

Figure 6/a. SBIF LIDAR Student Building 3. Floor CAD Plan.

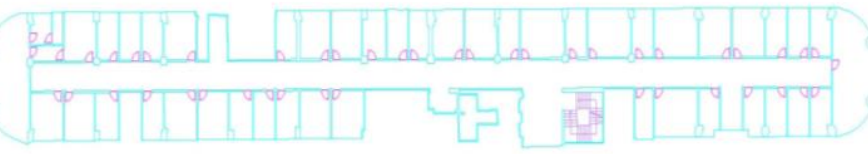

Figure 6/b. SBIF Administrative Building 4. Floor CAD Plan

Later, these floor plans were made $3 \mathrm{D}$ with the SketchUp software and a 3D model was created by combining all floor plans and the attic plan (Figure 7/a, 7/b, 7/c and 7/d).

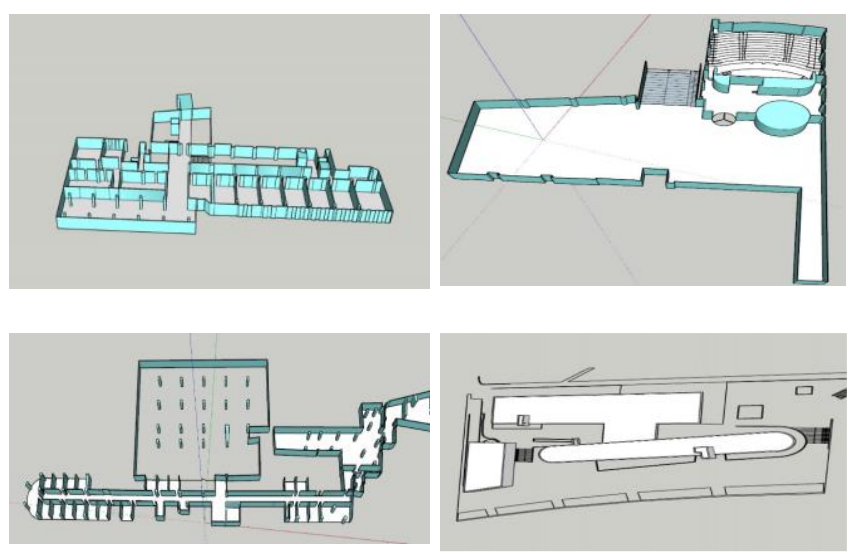

Figure 7/a. SBIF Student Building 2. Floor 3D Model, Figure 7/b. SBIF Middle Garden and Auditorium 3D Model, Figure 
7/c. SBIF Administrative Building Ground Floor 3D Model, Figure 7/d. SBIF Attic Floor Plan.

Finally; All floor plans were combined with the SketchUp software and the whole 3D model is created and shown in figure $8 / \mathrm{a}$ and $8 / \mathrm{b}$.
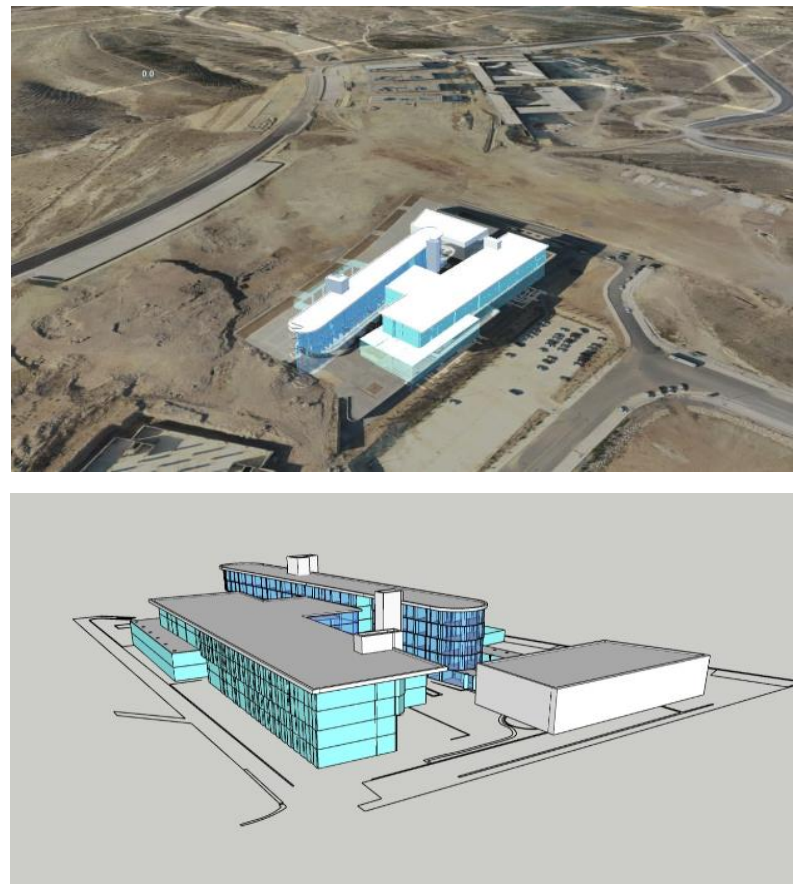

Figure 8/a. SBIF 3D Model with Orthophoto, Figure 8/b. SBIF 3D Model.

As seen in Figure 8/b, a 3D model was produced, and analyses were made in order to comment on the scope of the 3D model produced from LIDAR data. First of all, approximately $91 \%$ of the building was scanned with LIDAR and turned into a 3D model. Some private/secret rooms and toilets for privacy reasons were not scanned, other than that almost the entire building was modelled as shown in Table 3.

\begin{tabular}{|l|l|l|l|l|l|l|}
\hline No & Section & Floor & $\begin{array}{l}\text { Total } \\
\text { Area }\end{array}$ & $\begin{array}{l}\text { Scanned } \\
\text { Area }\end{array}$ & $\begin{array}{l}\text { Unscanned } \\
\text { Area }\end{array}$ & $\begin{array}{l}\text { Scan } \\
\text { Rate }\end{array}$ \\
\hline 1 & $\begin{array}{l}\text { Administrative } \\
\text { Building }\end{array}$ & 4 & 1135,388 & 1015,196 & 120,192 & $89,41 \%$ \\
\hline 2 & $\begin{array}{l}\text { Administrative } \\
\text { Building }\end{array}$ & 3 & 1255,804 & 1140,731 & 115,073 & $90,84 \%$ \\
\hline 3 & $\begin{array}{l}\text { Student } \\
\text { Building }\end{array}$ & 3 & 1921,826 & 1828,39 & 93,436 & $95,14 \%$ \\
\hline 4 & $\begin{array}{l}\text { Administrative } \\
\text { Building }\end{array}$ & 2 & 1238,417 & 1093,641 & 144,776 & $88,31 \%$ \\
\hline 5 & $\begin{array}{l}\text { Student } \\
\text { Building }\end{array}$ & 2 & 2218,249 & 2068,89 & 149,359 & $93,27 \%$ \\
\hline 6 & $\begin{array}{l}\text { Administrative } \\
\text { Building }\end{array}$ & 1 & 801,648 & 709,464 & 92,184 & $88,50 \%$ \\
\hline 7 & $\begin{array}{l}\text { Student } \\
\text { Building }\end{array}$ & 1 & 2733,047 & 2555,329 & 177,718 & $93,50 \%$ \\
\hline 8 & $\begin{array}{l}\text { Administrative } \\
\text { Building }\end{array}$ & Ground & 4394,28 & 4038,475 & 355,805 & $91,90 \%$ \\
\hline 9 & $\begin{array}{l}\text { Student } \\
\text { Building }\end{array}$ & Ground & 2655,334 & 2172,494 & 482,84 & $81,82 \%$ \\
\hline 10 & Auditorium & Ground & 607,218 & 572,739 & 34,479 & $94,32 \%$ \\
\hline Totally & & $\mathbf{1 8 9 6 1 , 2 1 1}$ & $\mathbf{1 7 1 9 5 , 3 4 9}$ & $\mathbf{1 7 6 5 , 8 6 2}$ & $\mathbf{9 0 , 6 9 \%}$ \\
\hline
\end{tabular}

\section{CONCLUSION}

As a result; a study was carried out on a total area of $40,000 \mathrm{~m}^{2}$, $20,000 \mathrm{~m}^{2}$ of which is indoor and $20,000 \mathrm{~m}^{2}$ of which is outside. It has been seen that both data can be integrated with each other and it has been understood that photogrammetric models can be used easily in 3D Urban Models / 3D Cadastre studies, and photogrammetric data is an important data production technique for Building Information Modelling (BIM) and can be easily used in housing stock and quality studies.

In the study, while evaluating the data obtained from both systems (LIDAR and UAV), the advantages and disadvantages of the systems were also examined. Firstly, both systems gave very successful results in outdoor 3D modelling. However, with the UAV system, the data required for 3D modelling can be obtained faster and the data is processed faster. In the scanning process with a hand-held LIDAR scanner, there were some deficiencies in the corners of the buildings, the corners of the roofs, the joints of the columns, due to the measurement principle of the TLS system.

The Zeb-Revo handheld LiDAR system was tested in outdoor conditions for mapping purposes. Outdoors, the scanner's range was a maximum of $20 \mathrm{~m}$ (effective distance $15 \mathrm{~m}$ ). A planar surface was created from a distance of less than $6 \mathrm{~m}$ and it was determined that the deviation in the points did not exceed $8 \mathrm{~cm}$ according to the square mean error value. The standard deviation value in forming the plane was obtained as $9 \mathrm{~mm}$. It provides sufficient accuracy criteria for plane or line extraction from the point cloud. The mapping performance with the handheld LiDAR Zeb-Revo GeoSLAM is comparable to other systems, demonstrating the feasibility of repositioning by synchronizing with any point cloud. Absolute position accuracies can be increased with indirect coordinating methods. In addition, it has been seen that the known classification and filtering methods form reliable clusters, and the production of topographic and 2D maps for the needs after the classification meets the standards. In the UAV system, the missing places in the TLS lidar systems were successfully measured in this system, provided that the top scan and oblique pictures were taken on the lateral surfaces. This study will benefit studies involving larger areas as this is not a relative study at LoD 4 level.

\section{ACKNOWLEDGEMENTS}

This article was produced from the first author's PhD thesis.

\section{REFERENCES}

C Dewez, T. J. B., Yart, S., Thuon, Y., Pannet, P., \& Plat, E. (2017). Towards cavity-collapse hazard maps with Zeb-Revo handheld laser scanner point clouds. The Photogrammetric Record, 32(160), 354-376. doi:10.1111/phor.12223

Doğru, A. Ö., Şeker, D. Z. (2009). Coğrafi Bilgi Sistemlerinde 3B Kent Modelleme Olanaklarının İrdelenmesi, TMMOB 2009 Coğrafi Bilgi Sistemleri Kongresi, İzmir.

Döllner, J., Kolbe, T. H., Liecke, F., Sgouros, T. ve Teichmann, K., 2006, The Virtual 3D City Model of Berlin- Managing, Integrating, and Communicating Complex Urban Information, Proceedings of the 25th Urban Data Management Symposium, May, Aalborg, 15-27.

Table 3. Status of the Photogrammetric Model. 
Emem, O., Batuk, F. and Ayazlı, İ. E., 2008. UKVA Kapsamında UVDF-GML Tasarımı, HKM Jeodezi, Jeoinformasyon ve Arazi Yönetimi Dergisi, 2, 99.

Geo-SLAM. (2019). Zeb-Revo Retrieved from http://geoslam.com/hardware-products/zeb-revo/

Isikdag, U. and Zlatanova, S., 2009. "Towards defining a framework for automatic generation of buildings in CityGML using Building Information Models". In: Lee, J. and Zlatanova, S. (eds.) 3D Geo-Information Sciences, Lecture Notes in Geoinformation and Cartography, Springer: Berlin, 79-96.

Karasaka, L. and Beg, A. R., 2021 Zeybek, M. 2019. Modeling of different geometrical properties by terrestrial laser scanning. Journal of Geomatics-2021-6(1).

Karsl1, F., 2020, Fotogrametri, İstanbul University Lesson Book, , 29-30.

Kolbe, T. H., Gröger, G. and Plümer, L., 2005. CityGML Interoperable Access to 3D City Models, Proceedings of the Int. Symposium on Geo-information for Disaster Management, Delft, March, 21-23.

Laguela, S., Dorado, I., Gesto, M., Arias, P., GonzalezAguilera, D., \& Lorenzo, H. (2018). Behavior Analysis of Novel Wearable Indoor Mapping System Based on 3D-SLAM. Sensors (Basel), 18(3). doi:10.3390/s18030766

Mao, B., 2011. Visualisation and Generalisation of 3D City Models, Doctora Thesis, K.T.H., Stockholm.

Özdoğan, Ş. and Başaraner, M., 2013. CityGML Standardında Ayrıntı Düzeylerinin Modellenmesi, TMMOB Coğrafi Bilgi Sistemleri Kongresi, Ankara, Kasım.

Sadek, E. S. S. M., Ali. S. J. B. S., Rosdi, B. ve Kadzim, M. R. B. M. D, 2002. The Design and Development of a Virtual 3D City Model, 1-12.

Sammartano, G., \& Spanò, A. (2018). Point clouds by SLAMbased mobile mapping systems: accuracy and geometric content validation in multisensor survey and stand-alone acquisition. Applied Geomatics. doi:10.1007/s12518-018-0221-7

Yücel, M. A. and Selçuk, M., 2009. Üç Boyutlu Kent Modellerinde Ayrıntı Düzeyi (LoD) Kavramı, HKM Jeodezi, Jeoinformasyon ve Arazi Yönetimi Dergisi 2,101.

Zeybek, M. 2019. Hand-held LiDAR measurement systems and 3D data processing. Turkey Lidar Journal-2019-1. 